\title{
High expression of uPA related to P38MAPK in esophageal cancer indicates poor prognosis
}

This article was published in the following Dove Press journal:

OncoTargets and Therapy

\author{
Qilong Liu',* \\ Wenfeng $\mathrm{Li}^{1, *}$ \\ Shibin Yang ${ }^{\prime}$ \\ Zhaoguo Liu ${ }^{2}$ \\ 'Department of Gastrointestinal \\ Surgery, First Affiliated Hospital, \\ Sun Yat-sen University, Guangzhou \\ 510089, Guangdong, China; \\ ${ }^{2}$ Department of General Thoracic \\ Surgery, First Affiliated Hospital, \\ Sun Yat-sen University, Guangzhou \\ 5I0089, Guangdong, China \\ *These authors contributed equally \\ to this work
}

\begin{abstract}
Background: The aim of the study was to investigate the relationship between urokinase-type plasminogen activator (uPA) and mitogen-activated protein kinase 38 (p38MAPK), and preliminarily analyze their relationship with clinical characteristics of esophageal cancer.

Materials and methods: Immunohistochemistry and Western blot were used to detect the expressions of uPA and p38MAPK in patients with esophageal cancer. The relationship between them and clinicopathological features was analyzed by chi-squared test and Spearman correlation. Prognosis was performed using Kaplan-Meier and Cox proportional hazard models analysis. Results: The expressions of uPA and p38MAPK proteins were significantly higher in esophageal squamous cell carcinoma or adenocarcinoma than in normal esophageal mucosa tissue (both $P<0.0001)$. The expression of uPA was significantly correlated with the depth of invasion of esophageal cancer $(P=0.0067)$, tumor size $(P=0.0364)$, and pathological stage $(P<0.0001)$; p38MAPK expression vs esophageal cancer tissue type $(P=0.0043)$, esophageal cancer infiltration depth $(P=0.0097)$, tumor size $(P=0.0015)$, and pathological stage $(P<0.0001)$. Both were not significantly associated with lymph node staging, gender, age, and esophageal cancer histological type. There was a positive correlation between uPA and p38MAPK expressions ( $r=0.7301, P=0.0104)$. Kaplan-Meier analysis showed that the overall survival time of patients with positive expression of uPA or p38MAPK protein was significantly shorter, and the time of recurrence or metastasis of esophageal cancer was significantly earlier in patients with uPApositive expression. Multivariate analysis of Cox model showed that uPA, p38MAPK, and pathological staging were independent factors influencing survival.
\end{abstract}

Conclusion: The expressions of uPA and p38MAPK may play an important role in the progression of esophageal cancer, and there is a close relationship between the two proteins, which may be one of the prognostic indicators.

Keywords: esophageal cancer, urokinase-type plasminogen activator, mitogen-activated protein kinase 38, prognosis

\section{Introduction}

Esophageal cancer is one of the most common malignant tumors of the digestive system in the world. There are about 240,000 new cases of esophageal cancer in China every year. ${ }^{1-3}$ According to statistics, its 5-year survival rate is 3.5\%-13.9\% in Xinjiang. The cancer mortality rate is $13.05 / 100,000$, of which the Kazakh (Ha) mortality rate is $68.88 / 100,000$, which seriously threatens people's health. ${ }^{4-6}$

Since the study in 1976 that urokinase-type plasminogen activator (uPA) is present in human ovarian tumor cells, the relationship between uPA and tumor invasion and metastasis has been paid more and more attention. It is widely distributed in human tumor cells. The expression level in malignant tumor tissues is higher than that in their corresponding normal tissues. ${ }^{7,8}$ The uPA system may regulate angiogenesis, invasion,
Correspondence: Zhaoguo Liu Department of General Thoracic Surgery, First Affiliated Hospital, Sun Yat-sen University, 58 Zhongshan 2nd Road, Guangzhou 510089, Guangdong, China Tel +860208733 4525

Email liuzhaoguo322@163.com (c) (7) (9) 2018 Liu et al. This work is published and licensed by Dove Medical Press Limited. The full terms of this license are available at https://www.dovepress.com/terms.php cc. hereby accept the Terms. Non-commercial uses of the work are permitted without any further permission from Dove Medical Press Limited, provided the work is properly attributed. For permission for commercial use of this work, please see paragraphs 4.2 and 5 of our Terms (https://www.dovepress.com/terms.php). 
and metastasis of digestive tract tumors in a variety of ways, and is related to monocyte activation antigen and matrix metalloproteinase production. ${ }^{9}$ Studies have shown that ${ }^{10} \mathrm{uPA}$ mainly participates in the inhibition of excessive degradation of extracellular matrix (ECM) through the urokinase-type plasminogen activator receptor (uPAR)/plasminogen activator inhibitor type 1 (PAI-1) complex, thereby inhibiting tumor metastasis. Recently, more studies have shown ${ }^{11-14}$ that uPA may be associated with the mitogen-activated protein kinase 38 (p38MAPK) signaling pathway in a variety of tumor progression, and is found to be highly expressed in both tumors and associated with clinical stage and lymph node metastasis, such as in breast cancer, ovarian cancer, and lung cancer. It was also found that blocking the p38MAPK signaling pathway in ovarian cancer, can inhibit uPA expression. The p38MAPK signaling pathway can inhibit uPA expression. Although some progress has been made on this research, there are few more detailed studies on them, such as whether p38MAPK participates in the formation of uPA/uPAR/PAI-1 and affects the degradation of the outer matrix (ECM), or their relationship in the esophagus carcinoma progression.

P38 is an important member of the mitogen-activated protein kinase (MAPK), which has six isoforms, p38 $\alpha 1$, $\mathrm{p} 38 \alpha 2, \mathrm{p} 38 \beta 1, \mathrm{p} 38 \beta 2, \mathrm{p} 38 \gamma$, and p38 $\delta$. Studies have found that extracellular stimuli such as cytokines and bacterial pathogens can activate the phosphorylation of the Thr site of p38MAPK, which transduces signals to the nucleus to initiate related target genes to promote transcription. ${ }^{15-17}$ p38MAPK is known to be involved in a variety of different biological processes, including promoting apoptosis, participating in inflammatory reactions, malignant tumor development, and regulating transcription and translation of many different proteins, but its research in esophageal cancer is relatively rare. In our previous study, we found that uPA and p38MAPK may be closely related to esophageal cancer. The purpose of this study was to investigate the relationship between the two in esophageal cancer and its relationship with clinicopathological features and prognosis of esophageal cancer.

\section{Materials and methods Materials}

One hundred eighty-four cases of esophageal cancer specimens confirmed by pathology in the First Affiliated Hospital of Sun Yat-sen University from 2007 to 2011 and 62 cases of adjacent normal tissues ( $>5 \mathrm{~cm}$ from the edge of esophageal cancer, pathologically confirmed normal mucosal tissue) were selected. All cases were not given any radiotherapy or chemotherapy before surgery. According to the TNM standard staging of the eighth edition of esophageal cancer in 2017, gender, age, degree of cell differentiation, tissue type, depth of invasion, and pathological staging were selected as clinical characteristic parameters. Follow-up was by telephone and mail; overall survival was calculated from the date of diagnosis to death or August 2, 2017. Progression-free survival begins with treatment of esophageal cancer patients, until observation progression or death or until August 2, 2017. There were no cases of loss of follow-up. The uPA mouse antihuman monoclonal antibody (sc-59727, concentrated) was purchased from Santa Cruz Biotechnology Inc., Dallas, TX, USA mouse antihuman p38MAPK (AN1020) was from Abgent, San Diego, CA, USA. The ready-to-use Elivision mainly includes the following: avidin (Reagent A), biotin-horseradish peroxidase (anti-mouse/rabbit IgG, Reagent B), which is purchased from Fuzhou Maixin Biotechnology Development Co., Ltd. with DAB staining solution (Fuzhou Maixin Biotechnology Development Co., Ltd). B-actin antibody was purchased from Beijing Zhongshan Biotechnology Company. Immunoblot chemiluminescence reagent (enhanced chemiluminescence [ECL] reagent) was purchased from Jiangsu Biyuntian Biotechnology Research Institute. Polyvinylidene fluoride or polyvinylidene difluoride (PVDF) membranes were purchased from Millipore, Burlington, MA, USA.

\section{Immunochemistry}

Specimens were fixed in 10\% formalin, embedded in paraffin, and made into 3-4- $\mu \mathrm{m}$-thick paraffin sections. According to Elivision method, paraffin sections were placed in an oven at $67^{\circ} \mathrm{C}$ for 2 hours, dewaxed and hydrated, rinsed with $7.4 \mathrm{pH}$ PBS for 3 times, 3 minutes each time, then antigen repair. One drop of $3 \% \mathrm{H}_{2} \mathrm{O}_{2}$ was added to each section and incubated for 10 minutes at room temperature to block endogenous peroxidase activity, and rinsed with PBS for 3 times, 3 minutes each time. Then, PBS was removed and primary antibody anti-uPA (1:200) and anti-p38MAPK (1:150) - was added dropwise and incubated for 2 hours at room temperature. Washed with PBS for 3 times, 5 minutes each time. PBS was removed, reagent $\mathrm{A}$ added, incubated at room temperature for 20 minutes, rinsed with PBS for 3 times, 3 minutes each time. PBS was removed, reagent B added, incubated at room temperature for 30 minutes, then rinsed with PBS for 3 times, 5 minutes each time. Counterstained with hematoxylin, $0.1 \%$ HCL differentiation, rinsed with distilled water, dehydrated with gradient alcohol, transparent with xylene, sealed with neutral gum, observed after drying. 


\section{Result evaluation}

The results were independently read by three pathologists and scored according to the intensity of staining and the percentage of positive cells. Ten high-power fields of each slice were selected, and the percentage of positive cells was counted. The scoring criteria were as follows: no positive cells, $0 ; \leq 25 \%, 1 ; 25 \%-50 \%, 2 ; 50 \%-75 \%, 3 ;>75 \%, 4$. Staining intensity score criteria: no coloring, 0 ; light yellow, 1 ; brownish yellow, 2 ; tan, 3 . The final staining results were multiplied by the percentage of positive cells and staining intensity, with $0-2$ being negative and $\geq 3$ being positive.

\section{Western blotting}

One hundred microliters of RIPA lysate was added to $20 \mathrm{mg}$ of tissue, homogenized on ice, centrifuged at $12,000 \mathrm{rev} /$ minute for 10 minutes at $4^{\circ} \mathrm{C}$, and the supernatant was separated to determine the protein concentration. The protein was separated by $10 \%$ SDS-PAGE electrophoresis with a loading of $40 \mu \mathrm{g}$ in a volume of $20 \mu \mathrm{L}$. After the electrophoresis, a "sandwich" was prepared, and the protein was electrotransferred to the PVDF membrane. After blocking with 5\% nonfat dry milk for 2 hours, added anti-uPA (1:600), anti-p38MAPK (1:500), and mouse anti- $\beta$-actin (clone AC-15; 1:10,000, Sigma-Aldrich). After washing the membrane, added the secondary antibody, incubated for 50 minutes at room temperature on the shaker. At the end, the membrane was washed five times with TBST for 5 minutes each time, and the ECL was exposed. Gelpro 32 analysis was performed for gel image analysis.

\section{Statistical methods}

Data were analyzed using Graphpad Prism 6.0 software. Count data were expressed as rates and chi-squared tests were used for comparison between groups. Spearman test was used for correlation analysis and Kaplan-Meier and Cox proportional hazards regression were used for univariate and multivariate analyses. $P<0.05$ was considered statistically significant. "*" stands for " $P<0.01$," "***" stands for " $P<0.001$," “***" stands for " $P<0.0001$."

\section{Results}

\section{Expressions of uPA and p38MAPK in esophageal cancer and adjacent tissues}

After immunohistochemistry test, according to the above methods, the expressions of uPA and p38MAPK in esophageal squamous cell carcinoma and adenocarcinoma were found to be higher than those in normal esophageal tissues (both
$P<0.0001$ ): uPA (squamous cell carcinoma: $89 / 112$, adenocarcinoma: 61/72, and normal tissue: $15 / 62$ ) and p38MAPK (squamous cell carcinoma: 92/112, adenocarcinoma: 61/72, normal tissue: 20/62). Further detection by Western blot found similar results, compared with normal esophageal tissue; the expression of uPA or p38MAPK protein in esophageal squamous cell carcinoma or adenocarcinoma was higher than that of normal esophageal tissue, and all $P$-value $<0.0001$ (Table 1 and Figure 1).

\section{Relationship between uPA and P38MAPK and their relationship with clinicopathological parameters}

After further analysis, it was found that there was a close correlation between the expressions of uPA and p38MAPK in esophageal cancer tissues $(r=0.7301, P=0.0104$, Table 1$)$. At the same time, uPA expression was significantly different between esophageal cancer infiltration depth ( $T$ stage, $P=0.0067)$, tumor length $(P=0.0364)$, and pTNM stage $(P<0.0001)$, but there was no significant relationship between tissue type, morphologic type, lymph node staging, gender, and age. p38MAPK expression was correlated with esophageal cancer infiltration depth (T stage, $P=0.0097$ ), tumor length $(P=0.0015)$, pTNM stage $(P<0.0001)$, and tissue type $(P=0.0043)$, but it was also not significantly associated with morphologic type, age, gender, and lymph node staging (Table 2).

\section{Relationship between uPA, p38MAPK, and prognosis in patients with esophageal cancer}

After Kaplan-Meier analysis, the survival time of uPA- and p38MAPK-positive expression patients was found to be significantly shorter than that of negative patients (former, median survival: 42 vs 96 months, $P<0.0001$; latter, median survival: 45 vs 78 months, $P=0.0121$ ). At the same time, it was found that patients with uPA-positive expression had a shorter progression-free time than negative patients (Median time: 16 vs 70 months, $P=0.0032$ ), whereas there was no significant difference between p38MAPK-positive and p38MAPK-negative patients (Figure 2 and Table 3).

Cox multivariate regression analysis was performed based on patient age, gender, depth of tumor invasion, lymph node metastasis, lesion length, pTNM, uPA, and p38MAPK protein expressions. The results showed that uPA, p38MAPK protein expressions, and pTNM staging were independent prognostic factors (Table 3). 
A1
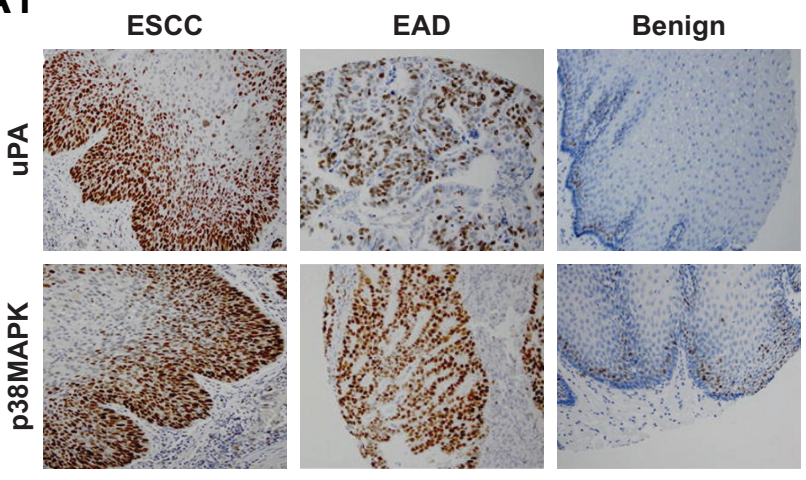

B1

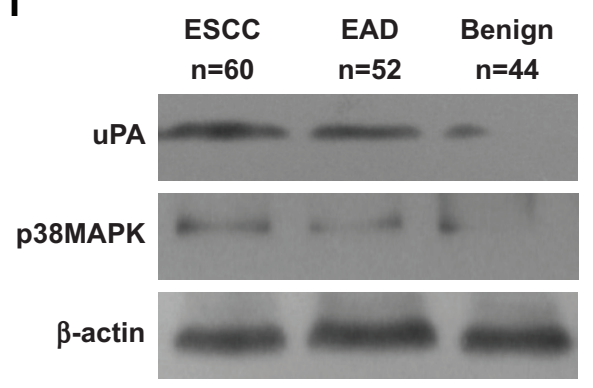

A2

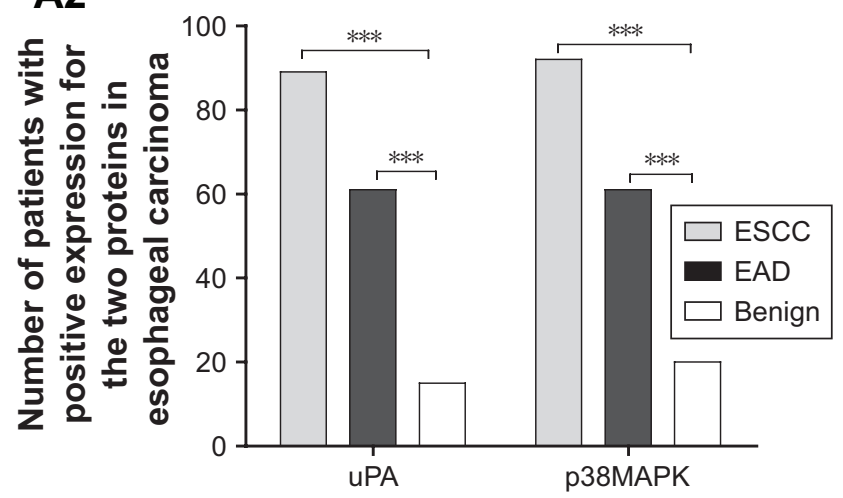

B2

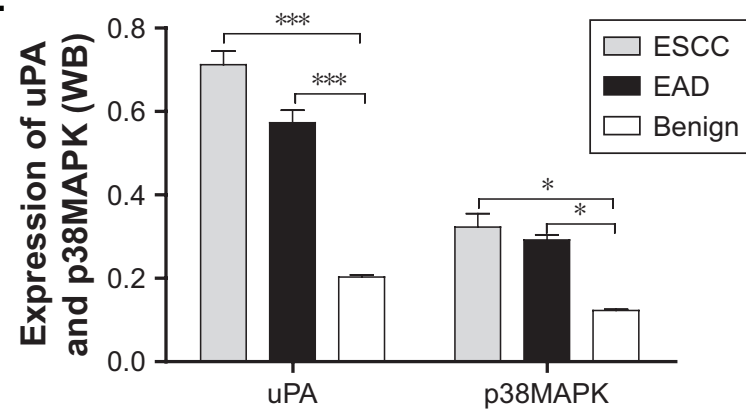

Figure I uPA and P38MAPK expressions in esophageal cancer via IHC and WB.

Notes: According to the method, the expressions of the two proteins in esophageal cancer and adjacent normal tissues were analyzed. (AI, A2) The expressions of uPA and P38MAPK in ESCC, adenocarcinoma, and adjacent normal tissues $(\times 200)$ were observed. The analysis found that the expressions of both proteins in squamous cell carcinoma and adenocarcinoma were much higher than those in adjacent normal tissues. (BI, B2) The expressions of the two proteins in esophageal cancer were analyzed by Western blot, and similar results were obtained. $* * * P<0.000$ I.

Abbreviations: EAD, esophageal adenocarcinoma; ESCC, esophageal squamous cell carcinoma; IHC, immunohistochemistry; p38MAPK, mitogen-activated protein kinase 38; uPA, urokinase-type plasminogen activator; WB, Western blot.

\section{Discussion}

Esophageal cancer is one of the most common malignant tumors in the world and is one of the important threats to human life. ${ }^{18,19}$ At present, after extensive research, the diagnosis and treatment of esophageal cancer has been greatly expanded, mainly including chemotherapy and surgical treatment. However, the recurrence rate and metastasis rate are still high, which is an important limitation that restricts the therapeutic effect. ${ }^{20-22}$ This study explored the relationship between uPA, p38MAPK, and esophageal cancer, explored its possible mechanism, and provided a preliminary scientific basis for expanding the new diagnosis and treatment of esophageal cancer.

A number of studies have confirmed that uPA plays an important role in tumor progression in a variety of tissues, such as breast cancer and ovarian cancer, ${ }^{23-25}$ which is often

Table I Both proteins' expression in ESCC, EAD, and benign tissue

\begin{tabular}{|c|c|c|c|c|c|c|c|c|}
\hline \multirow{3}{*}{ Variable factors } & \multicolumn{4}{|c|}{ uPA } & \multicolumn{4}{|c|}{ p38MAPK } \\
\hline & \multicolumn{2}{|c|}{ ESCC } & \multicolumn{2}{|c|}{ EAD } & \multicolumn{2}{|c|}{ ESCC } & \multicolumn{2}{|c|}{ EAD } \\
\hline & + & - & + & - & + & - & + & - \\
\hline Cancer & 89 & 23 & 61 & 11 & 86 & 26 & 67 & 5 \\
\hline Benign & 15 & 47 & 15 & 47 & 20 & 42 & 20 & 42 \\
\hline$P$-value & \multicolumn{2}{|c|}{$<0.0001$} & \multicolumn{2}{|c|}{$<0.0001$} & \multicolumn{2}{|c|}{$<0.0001$} & \multicolumn{2}{|c|}{$<0.0001$} \\
\hline \multicolumn{9}{|c|}{ Spearman correlation $\mathrm{S}(\mathrm{r})$ between expressions of uPA and p38MAPK } \\
\hline \multicolumn{5}{|l|}{ Patients (n) } & \multicolumn{2}{|l|}{$\boldsymbol{R}$} & \multicolumn{2}{|c|}{$P$-value } \\
\hline uPA vs P38MAPK & \multicolumn{2}{|c|}{184} & & & \multicolumn{2}{|c|}{0.7301} & \multicolumn{2}{|c|}{0.0104} \\
\hline
\end{tabular}

Abbreviations: EAD, esophageal adenocarcinoma; ESCC, esophageal squamous cell carcinoma; P38MAPK, mitogen-activated protein kinase 38; uPA, urokinase-type plasminogen activator. 
Table 2 Correlation of uPA and p38MAPK with clinicopathologic parameters

\begin{tabular}{|c|c|c|c|c|c|c|}
\hline \multirow[t]{2}{*}{ Groups } & \multicolumn{2}{|c|}{ uPA } & \multirow[t]{2}{*}{$P$-value } & \multicolumn{2}{|c|}{ P38MAPK } & \multirow[t]{2}{*}{$P$-value } \\
\hline & - & + & & - & + & \\
\hline \multicolumn{7}{|l|}{ Gender } \\
\hline Male & 16 & 78 & \multirow[t]{2}{*}{0.7047} & 17 & 77 & \multirow[t]{2}{*}{0.6967} \\
\hline Female & 18 & 72 & & 14 & 76 & \\
\hline \multicolumn{7}{|l|}{ Age (years) } \\
\hline$<60$ & 14 & 81 & \multirow[t]{2}{*}{0.1890} & 16 & 79 & \multirow[t]{2}{*}{1.0000} \\
\hline$\geq 60$ & 20 & 69 & & 15 & 74 & \\
\hline \multicolumn{7}{|l|}{ Histological type } \\
\hline SCC & 23 & 89 & \multirow[t]{2}{*}{0.4388} & 26 & 86 & \multirow[t]{2}{*}{0.0043} \\
\hline$A D$ & 11 & 61 & & 5 & 67 & \\
\hline \multicolumn{7}{|c|}{ Morphologic type } \\
\hline Ulcer & 6 & 41 & \multirow[t]{4}{*}{0.5338} & 5 & 42 & \multirow[t]{4}{*}{0.2723} \\
\hline Fungoid & 9 & 36 & & 10 & 35 & \\
\hline Medullary & 12 & 38 & & II & 39 & \\
\hline Constriction & 7 & 35 & & 5 & 37 & \\
\hline \multicolumn{7}{|l|}{ T stage } \\
\hline $\mathrm{TI}+\mathrm{T} 2$ & 22 & 57 & \multirow[t]{2}{*}{0.0067} & 20 & 59 & \multirow[t]{2}{*}{0.0097} \\
\hline $\mathrm{T} 3+\mathrm{T} 4$ & 12 & 93 & & II & 94 & \\
\hline \multicolumn{7}{|l|}{$N$ stage } \\
\hline No & 20 & 68 & \multirow[t]{2}{*}{0.1848} & 18 & 70 & \multirow[t]{2}{*}{0.2402} \\
\hline $\mathrm{NI}-3$ & 14 & 82 & & 13 & 83 & \\
\hline \multicolumn{7}{|l|}{ Tumor size } \\
\hline$<3 \mathrm{~cm}$ & 22 & 66 & \multirow[t]{2}{*}{0.0364} & 23 & 65 & \multirow[t]{2}{*}{0.0015} \\
\hline$\geq 3 \mathrm{~cm}$ & 12 & 84 & & 8 & 88 & \\
\hline \multicolumn{7}{|l|}{ pTNM } \\
\hline 1 & 15 & 23 & \multirow[t]{4}{*}{$<0.0001$} & 13 & 25 & \multirow[t]{4}{*}{$<0.0001$} \\
\hline II & 13 & 34 & & 14 & 33 & \\
\hline III & 3 & 56 & & 3 & 56 & \\
\hline IV & 3 & 37 & & 1 & 39 & \\
\hline
\end{tabular}

Abbreviations: $A D$, adenocarcinoma; $\mathrm{P} 38 \mathrm{MAPK}$, mitogen-activated protein kinase 38; SCC, squamous cell carcinoma; uPA, urokinase-type plasminogen activator.

higher in cancer tissues than in normal tissues. For example, Goscinski et $\mathrm{al}^{26}$ found that the positive expression of uPA was significantly higher in patients with distant metastasis of esophageal squamous cell carcinoma than in patients without distant metastasis. The higher the tumorigenicity of esophageal squamous cell carcinoma with higher uPA expression, the stronger is the tumor invasiveness and the tumor growth, suggesting that uPA may be involved in the occurrence and development of esophageal squamous cell carcinoma, participating in tumor tissue angiogenesis, and facilitating tumor cell metastasis. These data are consistent with our findings. In this study, the expression of uPA in esophageal squamous cell carcinoma and adenocarcinoma was much higher than that in normal esophageal tissue, suggesting that it may bear an important role in esophageal cancer progression.

MAPK is an important key molecule in the cell signaling pathway. p38 is one of its family members. When activated by upstream signals, p38 transmits cytoplasmic signals to the nucleus, activates specific nuclear transcription factors, regulates target genes, and participates in regulating cell growth and differentiation. p38 has six different subtypes, and its biological effects may differ under different cells and stimuli. Kim et $\mathrm{al}^{27}$ found that inhibition of p38MAPK activity can reduce the ability of cancer cells to exercise and reduce invasion and metastasis. Studies on human choriocarcinoma have shown that activated $\mathrm{p} 38$ enhances the invasive behavior of human trophoblast cells and plays an important role in the formation of choriocarcinoma. ${ }^{15,16,28}$ This study showed that the expressions of uPA and p38MAPK in esophageal cancer tissues were much higher than those in adjacent normal esophageal tissues, suggesting that both proteins may play an important role in the progression of esophageal cancer. Further analysis revealed that there is a close positive correlation between the expressions of both proteins. These data suggest an important possibility: do not rule out the role of $\mathrm{UPA}$ and $\mathrm{p} 38 \mathrm{MAPK}$ in promoting the progression of esophageal cancer in the same pathway. Considering $\mathrm{p} 38 \mathrm{MAPK}$ as a key molecule for several important signaling pathways, ${ }^{29,30}$ we believe that uPA may be involved either upstream or downstream of it. The conclusion of this study has not been reported yet. Although this study only analyzes semiquantitative immunohistochemistry and there is no further observation and determination of the relationship between the two proteins, it provides an important direction for revealing the mechanism of esophageal cancer progression.

In further analysis of its relationship with clinical pathological parameters of patients with esophageal cancer, the close relationship between them is further indicated. We found that the positive expressions of $\mathrm{UPA}$ and $\mathrm{p} 38 \mathrm{MAPK}$ are closely related to the cancer size, depth of invasion, and pathological stage of esophageal cancer. This confirms that both proteins are involved in the progression of esophageal cancer, which is consistent with some conclusions about the relationship among uPA, p38MAPK, and esophageal cancer. ${ }^{31-33}$ In these studies, uPA or p38MAPK was also observed to be closely related to esophageal cancer size and pTNM staging. In this study, we also found that uPA has no significant relationship with esophageal cancer tissue type, and p38MAPK is relatively high in adenocarcinoma. This phenomenon has attracted our attention, which may suggest 
Overall survival

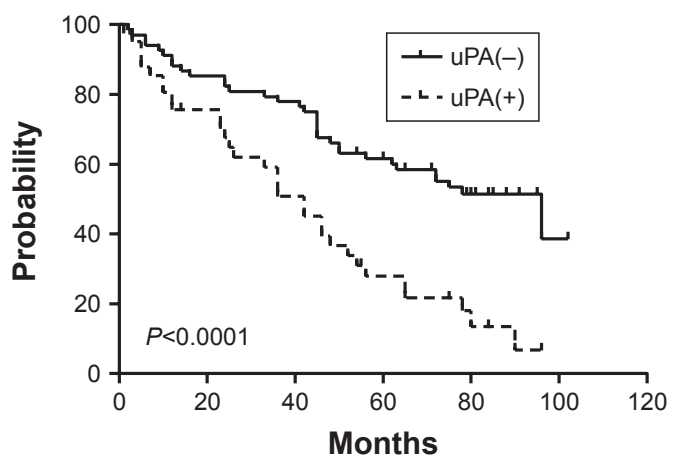

Progression-free survival

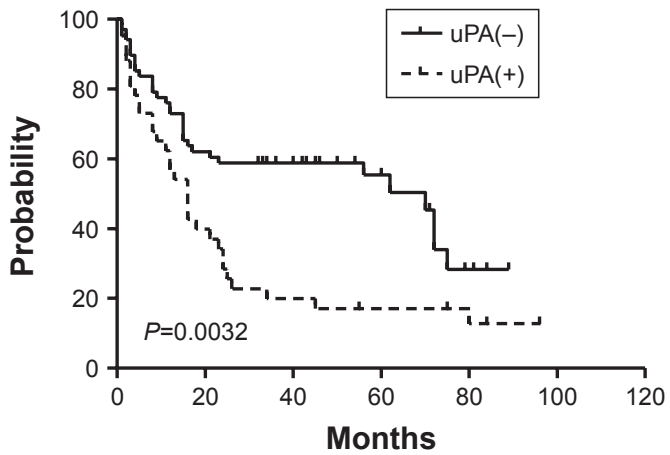

Overall survival

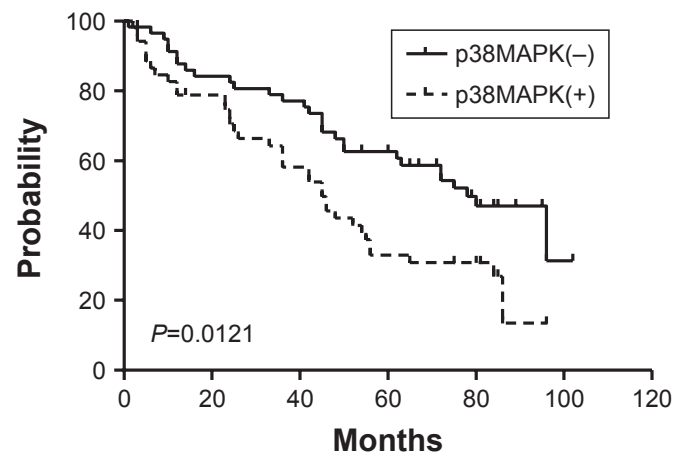

Progression-free survival

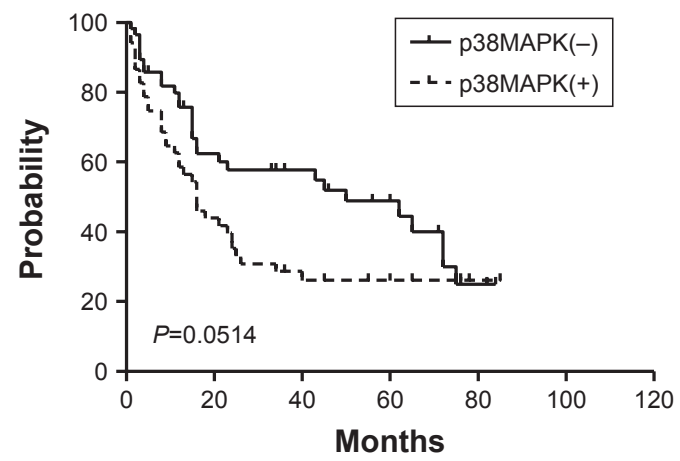

Figure 2 Analysis of the relationship between the two proteins and prognosis of esophageal cancer by Kaplan-Meier analysis.

Notes: The median survival time of patients with positive expression of both proteins was significantly shorter than that of patients with negative expression. Meanwhile, the time to progression of uPA-positive patients was shortened, but there was no significant difference between the time of progression of $\mathrm{p} 38 \mathrm{MAPK}$-positive patients and p38MAPK-negative patients.

Abbreviation: P38MAPK, mitogen-activated protein kinase 38; uPA, urokinase-type plasminogen activator.

Table 3 Kaplan-Meier and Cox multivariate proportional hazard analyses for overall survival

\begin{tabular}{|c|c|c|c|c|}
\hline \multirow[t]{2}{*}{ Factors } & \multicolumn{2}{|c|}{ Univariate analysis } & \multicolumn{2}{|l|}{ Multivariate analysis } \\
\hline & Log-rank & $P$-value & Hazard ratio $(95 \% \mathrm{Cl})$ & $P$-value \\
\hline \multicolumn{5}{|l|}{ Gender } \\
\hline Male & & & $0.8469(0.516 \mathrm{I}-1.390)$ & 0.5111 \\
\hline \multicolumn{5}{|l|}{ Female } \\
\hline \multicolumn{5}{|l|}{ Age (years) } \\
\hline$<60$ & & & $0.6673(0.404 I-I .102)$ & 0.1140 \\
\hline \multicolumn{5}{|l|}{$\geq 60$} \\
\hline \multicolumn{5}{|l|}{ Tumor size } \\
\hline$<3 \mathrm{~cm}$ & & & $0.7383(0.443 \mid-1.230)$ & 0.2442 \\
\hline \multicolumn{5}{|l|}{$\geq 3 \mathrm{~cm}$} \\
\hline \multicolumn{5}{|l|}{ uPA } \\
\hline Negative & 15.44 & $<0.0001$ & $0.3294(0.1893-0.5732)$ & 0.0302 \\
\hline \multicolumn{5}{|l|}{ Positive } \\
\hline \multicolumn{5}{|l|}{ P38MAPK } \\
\hline Negative & 6.300 & 0.0121 & $0.5253(0.3 \mid 77-0.8684)$ & 0.0122 \\
\hline \multicolumn{5}{|l|}{ Positive } \\
\hline \multicolumn{5}{|l|}{ PTNM } \\
\hline I-II & 8.425 & 0.0214 & $0.83 \mathrm{I} 5(0.502 \mathrm{I}-0.950 \mathrm{I})$ & 0.0413 \\
\hline III-IV & & & & \\
\hline
\end{tabular}

Abbreviations: p38MAPK, mitogen-activated protein kinase 38; uPA, urokinase-type plasminogen activator. 
that the role or mechanism of p38MAPK is subtly different in different tissue types of esophageal cancer tissues. There is no research on the mechanism of p38MAPK in different tissue types of esophageal cancer, which is worthy of further research.

In the analysis, we performed a complete prognosis of overall survival and progression-free prognosis for 184 patients. The similarity in characteristics and functions of the two were observed again. We found that the median survival time of patients with positive protein expression was significantly shortened, which is consistent with the above data and also with most of research on their relationship between single uPA or p38MAPK and esophageal cancer. ${ }^{31,34,35}$ At the same time, we found that only the uPA-positive patients had a significant reduction in the progression-free time, and the p38MAPK-positive patients did not significantly shorten the progression time. For the cause of this phenomenon, we consider not to rule out the possible errors caused by follow-up data collection (accurate time for progression-free progress has an error). In further Cox multivariate analysis, this study found that both proteins and pTNM staging can be used as independent prognostic factors for esophageal cancer.

In this study, we found that UPA and p38MAPK proteins may play important roles in the progression of esophageal cancer, and there may be synergistic effects in this process, which provide a new perspective for us to further explore the mechanism of esophageal cancer progression. At present, the diagnosis and treatment of esophageal cancer mainly depends on surgery and chemotherapy, which has a great impact on the quality of life of patients and has limitations. Therefore, these results are of great value to explore novel treatment methods. The role of uPA and p38MAPK in the progression of esophageal cancer may provide a scientific basis for exploring the feasibility of biologically targeted therapy for esophageal cancer.

\section{Ethical approval and written informed consent}

All procedures performed in the studies involving human participants were approved by the Ethics Committee of the First Affiliated Hospital, Sun Yat-sen University and conducted in accordance with the 1964 Helsinki declaration. Written informed consent was obtained from all participants included in the study.

\section{Acknowledgment}

This study is supported by National Nature Science Foundation of China (NSFC), grant number: 81501964.

\section{Disclosure}

The authors report no conflicts of interest in this work.

\section{References}

1. Daly JM, Fry WA, Little AG, et al. Esophageal cancer: results of an American College of Surgeons Patient Care Evaluation Study. J Am Coll Surg. 2000;190(5):562-572.

2. Dulak AM, Schumacher SE, van Lieshout J, et al. Gastrointestinal adenocarcinomas of the esophagus, stomach, and colon exhibit distinct patterns of genome instability and oncogenesis. Cancer Res. 2012; 72(17):4383-4393.

3. Cheng B, Yu J. Predictive value of diffusion-weighted MR imaging in early response to chemoradiotherapy of esophageal cancer: a metaanalysis. Dis Esophagus. Epub 2018 Jul 16.

4. Xie FJ, Zhang YP, Zheng QQ, et al. Helicobacter pylori infection and esophageal cancer risk: an updated meta-analysis. World J Gastroenterol. 2013;19(36):6098-6107.

5. Mao N, Nie S, Hong B, Li C, Shen X, Xiong T. Association between alcohol dehydrogenase-2 gene polymorphism and esophageal cancer risk: a meta-analysis. World J Surg Oncol. 2016;14(1):191.

6. Qiao GB, Han CL, Jiang RC, Sun CS, Wang Y, Wang YJ. Overexpression of $\mathrm{P} 53$ and its risk factors in esophageal cancer in urban areas of Xi'an. World J Gastroenterol. 1998;4(1):57-60.

7. Witzel ID, Milde-Langosch K, Wirtz RM, et al. Comparison of microarray-based RNA expression with ELISA-based protein determination of HER2, uPA and PAI-1 in tumour tissue of patients with breast cancer and relation to outcome. J Cancer Res Clin Oncol. 2010; 136(11):1709-1718.

8. Yong HY, Kim IY, Kim JS, Moon A. ErbB2-enhanced invasiveness of H-Ras MCF10A breast cells requires MMP-13 and uPA upregulation via p38 MAPK signaling. Int J Oncol. 2010;36(2):501-507.

9. Salas AL, Montezuma TD, Fariña GG, Reyes-Esparza J, RodríguezFragoso L. Genistein modifies liver fibrosis and improves liver function by inducing uPA expression and proteolytic activity in CCl4-treated rats. Pharmacology. 2008;81(1):41-49.

10. Tan X, Egami H, Nozawa F, Abe M, Baba H. Analysis of the invasion-metastasis mechanism in pancreatic cancer: involvement of plasmin(ogen) cascade proteins in the invasion of pancreatic cancer cells. Int J Oncol. 2006;28(2):369-374.

11. Estrella VC, Eder AM, Liu S, et al. Lysophosphatidic acid induction of urokinase plasminogen activator secretion requires activation of the p38MAPK pathway. Int J Oncol. 2007;31(2):441-449.

12. Roztocil E, Nicholl SM, Davies MG. Mechanisms of kringle fragment of urokinase-induced vascular smooth muscle cell migration. J Surg Res. 2007;141(1):83-90.

13. Randle DD, Clarke S, Henderson V, Odero-Marah VA. Snail mediates invasion through uPA/uPAR and the MAPK signaling pathway in prostate cancer cells. Oncol Lett. 2013;6(6):1767-1773.

14. Cai XD, Che L, Lin JX, et al. Krüppel-like factor 17 inhibits urokinase plasminogen activator gene expression to suppress cell invasion through the Src/p38/ MAPK signaling pathway in human lung adenocarcinoma. Oncotarget. 2017;8(24):38743-38754.

15. He J, Liu Z, Zheng Y, et al. p38 MAPK in myeloma cells regulates osteoclast and osteoblast activity and induces bone destruction. Cancer Res. 2012;72(24):6393-6402.

16. Tanaka Y, Gavrielides MV, Mitsuuchi Y, Fujii T, Kazanietz MG. Protein kinase $\mathrm{C}$ promotes apoptosis in $\mathrm{LNCaP}$ prostate cancer cells through activation of p38 MAPK and inhibition of the Akt survival pathway. J Biol Chem. 2003;278(36):33753-33762.

17. Uzgare AR, Kaplan PJ, Greenberg NM. Differential expression and/ or activation of P38MAPK, erk1/2, and jnk during the initiation and progression of prostate cancer. Prostate. 2003;55(2):128-139.

18. Baba Y, Baba H. Gene-expression signature may be useful for the prediction of lymph node metastasis in esophageal cancer. Ann Transl Med. 2018;6(11):230.

19. Jemal A, Murray T, Ward E, et al. Cancer statistics, 2005. CA Cancer J Clin. 2005;55(1):10-30. 
20. Li B, Xiang J, Zhang Y, et al. Comparison of Ivor-Lewis vs Sweet esophagectomy for esophageal squamous cell carcinoma: a randomized clinical trial. JAMA Surg. 2015;150(4):292-298.

21. Chen JW, Xie JD, Ling YH, et al. The prognostic effect of perineural invasion in esophageal squamous cell carcinoma. BMC Cancer. 2014;14:313.

22. Courrech Staal EF, van Coevorden F, Cats A, et al. Outcome of lowvolume surgery for esophageal cancer in a high-volume referral center. Ann Surg Oncol. 2009;16(12):3219-3226.

23. Duffy MJ, Mcgowan PM, Harbeck N, Thomssen C, Schmitt M. uPA and PAI-1 as biomarkers in breast cancer: validated for clinical use in level-of-evidence-1 studies. Breast Cancer Res. 2014;16(4):428.

24. Kuhn W, Pache L, Schmalfeldt B, et al. Urokinase (uPA) and PAI-1 predict survival in advanced ovarian cancer patients (FIGO III) after radical surgery and platinum-based chemotherapy. Gynecol Oncol. 1994;55(3 Pt1):401-409.

25. Ghasemi A, Hashemy SI, Aghaei M, Panjehpour M. RhoA/ROCK pathway mediates leptin-induced uPA expression to promote cell invasion in ovarian cancer cells. Cell Signal. 2017;32:104-114.

26. Goscinski MA, Suo ZH, Nesland JM, Flørenes VA, Giercksky KE. Dipeptidyl peptidase IV expression in cancer and stromal cells of human esophageal squamous cell carcinomas, adenocarcinomas and squamous cell carcinoma cell lines. APMIS. 2008;116(9):823-831.

27. Kim MS, Lee EJ, Kim HR, Moon A. p38 kinase is a key signaling molecule for H-Ras-induced cell motility and invasive phenotype in human breast epithelial cells. Cancer Res. 2003;63(17):5454-5461.

28. Xu Q, Tan Y, Zhang K, Li Y. Crosstalk between p38 and Smad3 through TGF- $\beta 1$ in JEG-3 choriocarcinoma cells. Int J Oncol. 2013; 43(4):1187-1193.
29. Liu Z, Yang W, Yang S, Cai K. The close association between IL-12Rß2 and p38MAPK, and higher expression in the early stages of NSCLC, indicates a good prognosis for survival. Mol Med Rep. 2018;18(2):2307-2313.

30. Cong N, Huang W, Yuan JP, et al. Peroxiredoxin1 promotes cell proliferation, migration and invasion of colorectal cancer via p38MAPK signaling. Eur Rev Med Pharmacol Sci. 2018;22(7):1922-1928.

31. Zhang Y, Feng Z, Wang W, et al. Expression of heat shock protein-27 (Hsp27) and P38MAPK in esophageal squamous cell carcinoma. Med Sci Monit. 2017;23:5246-5253.

32. Jiang JT, Zhang LF, Zhou B, et al. Relationships of uPA and VEGF expression in esophageal cancer and microvascular density with tumorous invasion and metastasis. Asian Pac J Cancer Prev. 2012; 13(7):3379-3383.

33. Yamashita K, Tanaka Y, Mimori K, Inoue H, Mori M. Differential expression of MMP and uPA systems and prognostic relevance of their expression in esophageal squamous cell carcinoma. Int J Cancer. 2004;110(2):201-207.

34. Looby E, Abdel-Latif MM, Athié-Morales V, et al. Deoxycholate induces COX-2 expression via Erk1/2-, p38-MAPK and AP-1-dependent mechanisms in esophageal cancer cells. BMC Cancer. 2009; 9:190.

35. Geng Y, Feng Y, Xie T, et al. Mapping the putative binding site for UPA protein in esophageal cancer-related gene 2 by heteronuclear NMR method. Arch Biochem Biophys. 2008;479(2):153-157.
OncoTargets and Therapy

\section{Publish your work in this journal}

OncoTargets and Therapy is an international, peer-reviewed, open access journal focusing on the pathological basis of all cancers, potential targets for therapy and treatment protocols employed to improve the management of cancer patients. The journal also focuses on the impact of management programs and new therapeutic agents and protocols on

\section{Dovepress}

patient perspectives such as quality of life, adherence and satisfaction The manuscript management system is completely online and includes a very quick and fair peer-review system, which is all easy to use. Visit http://www.dovepress.com/testimonials.php to read real quotes from published authors. 